Yasuyo Suzuki $\cdot$ Kazumi Oda $\cdot$ Yasuji Yoshikawa

Toyoki Maeda $\cdot$ Tomokazu Suzuki

\title{
A novel therapeutic trial of homogentisic aciduria in a murine model of alkaptonuria
}

Received: October 5, 1998 / Accepted: November 2, 1998

\begin{abstract}
Alkaptonuria is a rare autosomal recessive disorder characterized by homogentisic aciduria, ochronosis, and arthritis. Although a deficiency of homogentisic acid 1,2dioxygenase has recently been confirmed at the molecular level, no effective treatment regimen has yet been developed for this disorder. In the present study, 2(-2-nitro-4trifluoromethylbenzoyl)-1,3-cyclohexanedione (NTBC), a potent inhibitor of p-hydroxyphenylpyruvate dioxygenase (which catalyzes the formation of homogentisic acid from $\mathrm{p}$ hydroxyphenylpyruvic acid) was adopted as a possible therapeutic agent for alkaptonuria. NTBC dosedependently reduced the urinary output of homogentisic acid in a murine model of alkaptonuria that had been created with ethylnitrosourea. These findings suggest that NTBC may be the first potent pharmacotherapeutic agent for alkaptonuria.
\end{abstract}

Key words Alkaptonuria - Homogentisic acid - Treatment . NTBC $\cdot$ Murine model $\cdot$ Pharmacokinetics · Inborn error of metabolism

\section{Introduction}

Alkaptonuria (MIM no. 203500) represents a classical and widely known example of inborn errors of metabolism first proposed by Garrod (1908) at the beginning of the twentieth century. It is a rare autosomal recessive disorder character-

Y. Suzuki $\cdot$ K. Oda $\cdot$ T. Maeda $\cdot$ T. Suzuki ${ }^{1}(\bowtie)$

Department of Clinical Genetics, Medical Institute of Bioregulation, Kyushu University, Beppu, Japan

Tel. +81-977-27-1670; Fax +81-977-27-1671

e-mail:maeda@tsurumi.beppu.kyushu-u.ac.jp

Y. Yoshikawa

Diagnostic Laboratory, Medical Institute of Bioregulation, Kyushu

University, Beppu, Japan

Present address:

${ }^{1}$ Kinki Central Hospital, 3-1 Kurumazuka, Itami, Hyogo 664-8533, Japan Tel. +81-727-81-3712; Fax +81-727-79-1567

e-mail: dsuzuki@kich.itami.hyogo.jp ized by homogentisic aciduria (which causes a darkening of urine on prolonged exposure to air), ochronosis, and arthritis ( $\mathrm{La} \mathrm{Du} \mathrm{1995).} \mathrm{The} \mathrm{disease} \mathrm{is} \mathrm{caused} \mathrm{by} \mathrm{a} \mathrm{deficiency} \mathrm{of}$ homogentisic acid 1,2-dioxygenase (HGO. EC 1.13.11.5), which converts homogentisic acid (HGA) to maleylacetoacetic acid in the tyrosine degradation pathway ( $\mathrm{La} \mathrm{Du}$ et al. 1958) (Fig. 1). In 1996, Fernandez-Cañón and colleagues succeeded in verifying this phenotype at the molecular level.

Although alkaptonuria has been considered a relatively benign disorder, ochronotic arthritis can often be devastating and may result in patients becoming completely bedridden later in life (Kihara et al. 1994, La Du 1995, Fernandez-Cañón et al. 1996). No effective treatment for alkaptonuria has yet been found, despite various attempts to find a remedy ( $\mathrm{La} \mathrm{Du} \mathrm{1995).} \mathrm{In} \mathrm{this} \mathrm{regard,} \mathrm{we} \mathrm{have}$ recently noted that 2 (-2-nitro-4-trifluoromethylbenzoyl)1,3-cyclohexanedione (NTBC), a potent inhibitor of phydroxyphenylpyruvate dioxygenase (HPPD. EC 1.13.11. 27), which catalyzes the formation of HGA from $p$ hydroxyphenylpyruvic acid (Lindstedt et al. 1992) (Fig. 1), may be a suitable therapeutic agent for alkaptonuria. NTBC was used in five patients with hereditary tyrosinemia type 1 (fumarylacetoacetate hydrolase deficiency) (Lindstedt et al. 1992), and its efficacy, and safety were also demonstrated in a murine model of the same disorder (Grompe et al. 1995).

Here we describe the oral use of NTBC in a murine model of alkaptonuria (created with ethylnitrosourea by Montagutelli et al. 1994) and demonstrate that NTBC clearly corrects the underlying metabolic defect. Our findings suggest that NTBC may therefore be the first effective pharmacotherapeutic agent for alkaptonuria.

\section{Materials and methods}

Animals

Alkaptonuric mice were kindly provided by Dr. X. Montagutelli, of the Pasteur Institute. Mutant mice were 
Fig. 1 The action site of 2(-2nitro-4-trifluoromethylbenzoyl)1,3 cyclohexanedione $(N T B C)$ in tyrosine catabolism, including the steps required for the formation of ochronotic pigment in alkaptonuria. Break in arrow, block in alkaptonuria

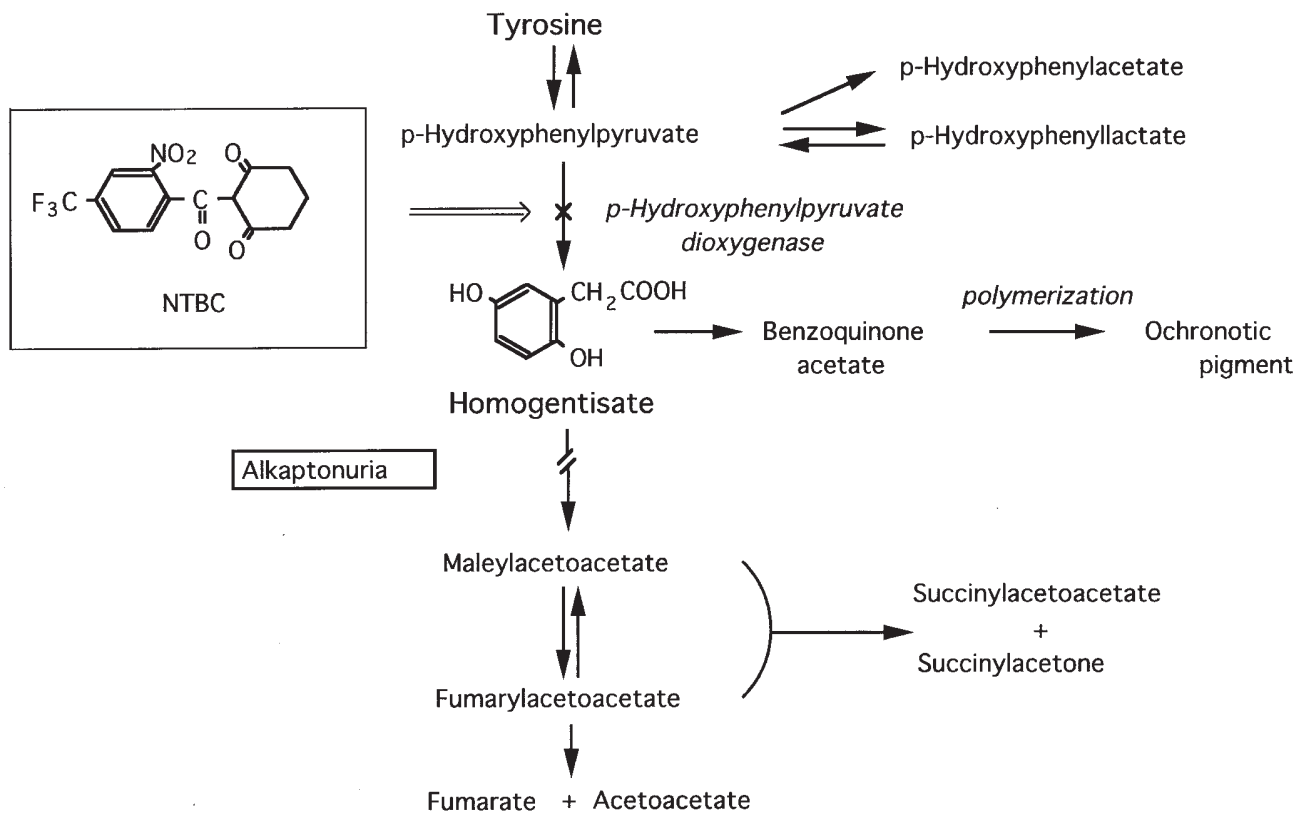

identified by the discoloration seen when a droplet of urine was deposited on filter paper impregnated with $0.5 \mathrm{M}$ $\mathrm{NaOH}$ and dried prior to use (Montagutelli et al. 1994). They were housed in metallic cages at $23^{\circ} \mathrm{C}$ under specific pathogen-free conditions, fed on CE-2 chow (Clea Japan, Tokyo), and used when they were 5-6 months of age.

\section{Reagents}

NTBC was synthesized in the laboratories of Sumitomo Pharmaceuticals (Osaka, Japan) for our experimental use. HGA and p-hydroxyphenyllactic acid (PHPL) were purchased from Sigma Chemical (St. Louis, MO, USA). p-Hydroxyphenylpyruvic acid (PHPP) and phydroxyphenylacetic acid (PHPA) were obtained from Wako Pure Chemical Industries (Osaka, Japan) and Nacalai Tesque (Kyoto, Japan), respectively. nHeptadecanoic acid was purchased from Pierce Chemical (Rockford, IL, USA). Bis (trimethylsilyl) trifluoroacetamide (BSTFA) and hydroxylamine $\mathrm{HCl}$ were obtained from Pierce Chemical and Wako Pure Chemical Industries, respectively.

\section{NTBC treatment}

NTBC was dissolved in $50 \mathrm{mM} \mathrm{NaHCO}$ and kept at $-20^{\circ} \mathrm{C}$ until use, as previously reported (Grompe et al. 1995). The mice received various doses of NTBC administered orally by a stomach tube either once or repeatedly.

\section{Determination of NTBC in plasma}

Fifty microliters of plasma was pipetted into plastic vials containing $50 \mu \mathrm{l}$ of $50 \mathrm{mM} \mathrm{NaHCO}$, and $50 \mu \mathrm{l}$ of acetonitrile was added for protein precipitation. The vials were then vortexed and centrifuged for $5 \mathrm{~min}$ at $15,000 \mathrm{rpm}$ at $4^{\circ} \mathrm{C}$. An aliquot $(50 \mu \mathrm{l})$ of the supernatant was injected into a highperformance liquid chromatograph (TOSOH SC-8010, Tosoh, Tokyo, Japan) with an ultraviolet (UV) detector and a Sumipax ODS A-212 column $(0.6 \times 15 \mathrm{~cm}$; Sumika Chemical Analysis Service, Osaka, Japan). The mobile phase consisted of an aqueous solution of $10 \mathrm{mM}$ sodium phosphate buffer $(\mathrm{pH} 7.40) /$ methanol $(60: 40, \mathrm{v} / \mathrm{v})$. The flow rate was set at $1.0 \mathrm{ml} / \mathrm{min}$. The peak NTBC was retained for $11.0 \mathrm{~min}$. The peak area of NTBC was linearly proportional to the amount of NTBC added to plasma at a range of $0-200 \mu \mathrm{g} /$ $\mathrm{ml}$. The minimum amount measured was $0.1 \mu \mathrm{g} \mathrm{NTBC} / \mathrm{ml}$ plasma. All plasma samples and solutions for calibration were prepared in duplicate.

Analysis of urinary organic acids

Urine was collected from the mice in the metabolic cages for 12 or $24 \mathrm{~h}$ in the presence of sodium metabisulfite (at least $1 \mathrm{mg} \mathrm{ml}^{-1}$ ) and liquid paraffin, and was then kept at $-20^{\circ} \mathrm{C}$ until analysis. An aliquot of urine was added, in duplicate, to n-heptadecanoic acid, an internal standard, and was then extracted with ethylacetate and diethyl ether. The combined extracts were concentrated to dryness under nitrogen gas, and trimethylsilylated with BSTFA for $1 \mathrm{~h}$ at $60^{\circ} \mathrm{C}$ before being submitted to gas chromatography/mass spectrometry (GC/MS). For the analysis of PHPP, the urine was reacted with hydroxylamine $\mathrm{HCl}$ prior to trimethylsilylation.

The GC/MS analysis was performed on a Hitachi G3000/M-2000A/ M-0201 apparatus (Hitachi, Tokyo, Japan). The chromatographic separation was carried out on a DB17 capillary column $(15 \mathrm{~m} \times 0.32 \mathrm{~mm}$ i.d., $0.5 \mu \mathrm{m}$ film thickness. J and W Scientific, Folsom, CA, USA), using helium as the carrier gas. The temperature was programmed from $100^{\circ} \mathrm{C}$ to $260^{\circ} \mathrm{C}$ at $6^{\circ} \mathrm{C} / \mathrm{min}$. The initial temperature was maintained for $4 \mathrm{~min}$. The temperature range for the HPPP 
analysis was $150^{\circ}-260^{\circ} \mathrm{C}$. The mass spectrometer was operated in the electron impact mode at an ion source temperature of $150^{\circ} \mathrm{C}$ and at an electron voltage of $70 \mathrm{eV}$. Four organic acids were assayed by selected ion monitoring. The monitor ions for PHPA, PHPL, HGA, and PHPP were $\mathrm{m} / \mathrm{z}$ 296, 308, 384, and 396, respectively.

We prepared the standard curves for the four organic acids in duplicate each time. The quantitative values for the organic acids were calculated by determining the peak area relative to the internal standard. The ratio was found to be linearly proportional to the amount of each organic acid added to distilled water in the range used for the analysis.

\section{Other biochemical analyses}

To examine the blood chemistry of the mice (bilirubin, aspartate aminotransferase [AST], creatinine, and amino acids), blood was collected from the orbital venous plexus with a capillary tube with the animals under general anaesthesia, and was immediately mixed with ethylenediaminetetraacetate (EDTA)-2Na. The plasma was frozen at $-20^{\circ} \mathrm{C}$ until used for analysis. Amino acid analysis of the plasma was done on a Hitachi automated amino acid analyzer.

\section{Histology}

The animals were anesthetized with diethyl ether and bled to death, and the liver, kidney, lumbar spine, knee, and ear were removed. Histology samples were fixed in $10 \%$ neutral buffered formalin, and stained with hematoxylineosin.

\section{Results}

Kinetics of a single oral dose of NTBC in control mice

One hundred $\mu \mathrm{g}$ of NTBC was given orally to 15 control mice, and the plasma concentration was observed 1, 3, 5, 8, and $12 \mathrm{~h}$ after this oral administration (Fig. 2). The plasma NTBC concentration reached a maximum at $1 \mathrm{~h}$ and gradually decreased thereafter. Trace amounts of NTBC remained in the blood $12 \mathrm{~h}$ after administration.

Metabolic effects of a single oral dose of NTBC in alkaptonuric mice

The urinary excretion of HGA, the hallmark metabolite of alkaptonuria, from alkaptonuric mice was markedly elevated during the control period (i.e., $24 \mathrm{~h}$ before dosing with NTBC began) (Fig. 3). The precursor intermediates of HGA (i.e., PHPP, PHPL, and PHPA) were also elevated at this time, compared with levels in the control mice. After a single oral $100-\mu \mathrm{g}$ dose of NTBC, a significant reduction in

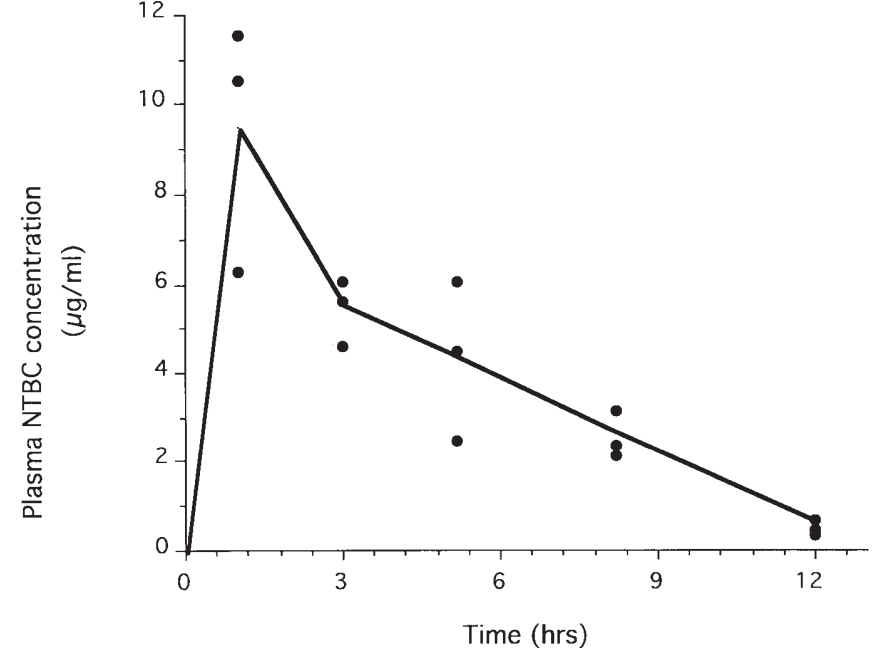

Fig. 2 Kinetics of a single 100- $\mu \mathrm{g}$ oral dose of NTBC in control mice. NTBC was well absorbed, and the maximum concentration in plasma was reached $1 \mathrm{~h}$ after dosage. Trace amounts of NTBC remained in the blood $12 \mathrm{~h}$ after administration

urinary HGA excretion and, inversely, a significant elevation of the three precursor intermediates were observed within $24 \mathrm{~h}$.

A single 100- $\mu \mathrm{g}$ dose of NTBC to an alkaptonuric mouse caused a dose-dependent reduction in urinary HGA output (Fig. 4). A single 100- $\mu \mathrm{g}$ dose of NTBC reduced the urinary HGA output to less than $2 \%$ of the pretreatment level $12-$ $24 \mathrm{~h}$ after dosing. With any dose of NTBC, the maximum reduction in urinary HGA output was observed $12-24 \mathrm{~h}$ after dosing.

In the time course of the urinary excretion of four tyrosine catabolites (i.e., PHPP, PHPL, PHPA and HGA), the peak PHPP value was reached within $12 \mathrm{~h}$ after a single oral 25 $\mu \mathrm{g}$ dose of NTBC, while the peak values for PHPL and PHPA were reached later, at 12-24h after dosing (Fig. 5).

Chronic effects of NTBC on biochemical and histologic findings in alkaptonuric mice

With the repeated administration of NTBC $25 \mu \mathrm{g}$ once daily (except at weekends) for 4 weeks in four alkaptonuric mice, there was a continuous reduction in urinary HGA output (Fig. 6).

Table 1 shows the effects of 5-week NTBC administration on plasma tyrosine levels and histological findings in the liver and kidney in alkaptonuric and control mice. Plasma tyrosine levels increased by about three times compared with levels before treatment in the NTBC-treated control mice, and by four to five times in alkaptonuric mice. Histologically, mild non-specific changes were observed in three of six livers and in one of six kidneys examined. No ochronotic joint lesions were observed in any of the alkaptonuric mice. X-ray examination of three alkaptonuric mice at age 13 months showed no calcification of the cartilage and no osteoarthritic changes in the knee and spine. 
Fig. 3 Urinary excretion of homogentisic acid (HGA), as homogentisate, and three precursor intermediates of HGA in alkaptonuric mice $24 \mathrm{~h}$ before and $24 \mathrm{~h}$ after single oral $100-\mu \mathrm{g}$ administration of NTBC. Values are expressed as means \pm SEM

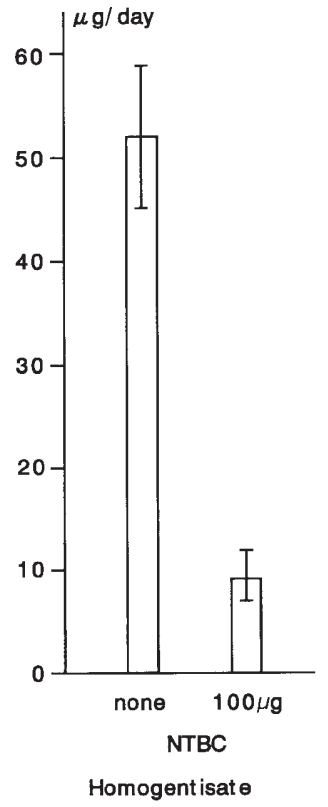

Homogentisate
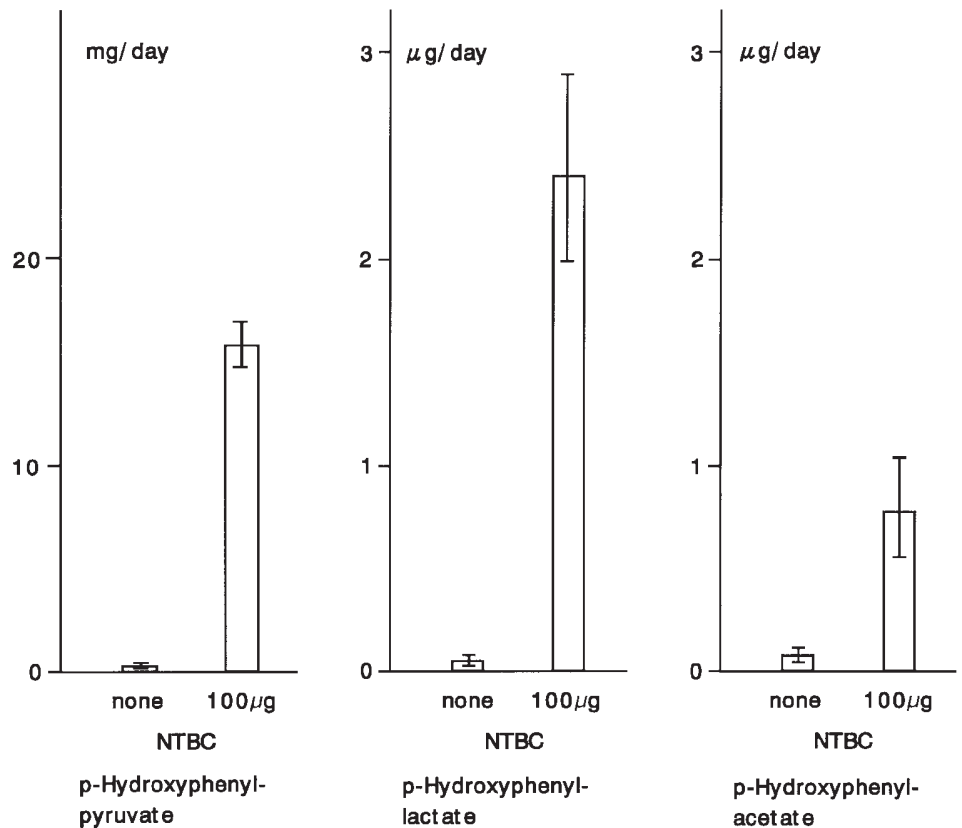

p-Hydroxyphenylacetate

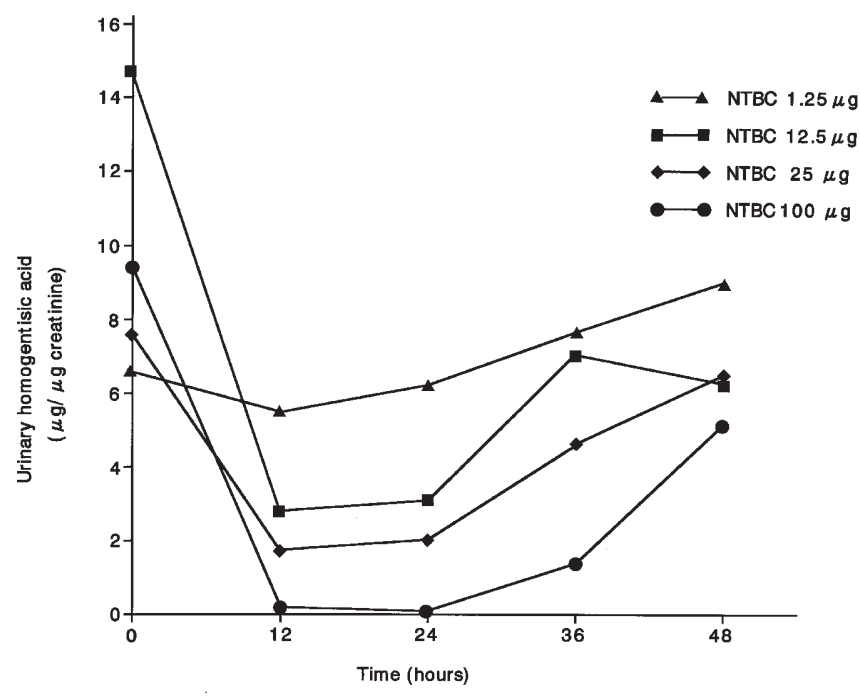

Fig. 4 Effects of various single oral doses of NTBC triangles, $1.25 \mu \mathrm{g}$; squares, $12.5 \mu \mathrm{g}$; diamonds, $25 \mu \mathrm{g}$; dots, $100 \mu \mathrm{g}$ ) on urinary HGA excretion in an alkaptonuric mouse

\section{Discussion}

Recent in-vitro studies of rat liver HPPD have shown that NTBC is a reversible inhibitor of this enzyme (Ellis et al. 1995, 1996). In the present study we confirmed this effect in vivo, showing an elevation of urinary PHPP, PHPL, and PHPA output and plasma tyrosine concentration after NTBC administration in control mice. Such an NTBCinduced metabolic profile is reminiscent of the HPPDdeficient mouse strain described by Endo et al. (1991). Furthermore, we also showed a distinct reduction in urinary HGA output after NTBC administration to alkaptonuric

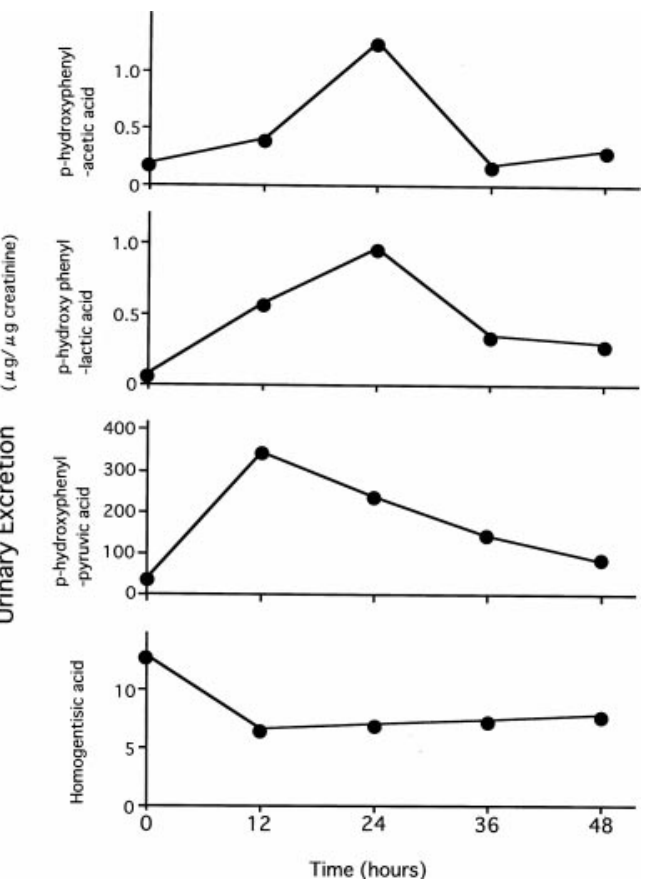

Fig. 5 Time course of the urinary excretion of HGA and its precursor intermediates in an alkaptonuric mouse after a single oral $25 \mu \mathrm{g}$ dose of NTBC. Peak excretions of p-hydroxyphenyllactic acid and phydroxyphenylacetic acid occurred later than that of p-hydroxyphenylpyruvic acid

mice. NTBC is thus the first compound that appears to have a definite pharmacotherapeutic effect on homogentisic aciduria in alkaptonuria.

However, the effectiveness of NTBC in treating ochronosis remains unknown, because no ochronotic lesions were observed in the alkaptonuric mice, as previously reported (Kamoun et al. 1992). The lack of ochronosis in alkaptonuric mice may reflect a species-specific characteris- 
Table 1 Effects of 5-week administration of NTBC on biological parameters in plasma and histological findings in alkaptonuric and control mice

\begin{tabular}{|c|c|c|c|c|}
\hline & \multicolumn{2}{|c|}{ Alkaptonuric mice } & \multicolumn{2}{|c|}{ Control mice } \\
\hline & $\begin{array}{l}\text { NTBC }(+) \\
(n=4)\end{array}$ & $\begin{array}{l}\operatorname{NTBC}(-) \\
(n=6)\end{array}$ & $\begin{array}{l}\operatorname{NTBC}(+) \\
(n=2)\end{array}$ & $\begin{array}{l}\text { NTBC }(-) \\
(n=2)\end{array}$ \\
\hline \multicolumn{5}{|l|}{ Plasma $^{a}$} \\
\hline Tyrosine $(\mathrm{nmol} / \mathrm{ml})$ & $414.9 \pm 61.0$ & $91.6 \pm 11.8$ & $257.2,327.2$ & $92.6,103.0$ \\
\hline $\operatorname{AST}(\mathrm{U} / \mathrm{I})$ & $69.5 \pm 8.4$ & $64.0 \pm 8.6$ & 90 & 123,66 \\
\hline Creatinine $(\mathrm{mg} / \mathrm{dl})$ & $0.3 \pm 0$ & $0.4 \pm 0.1$ & 0.3 & $0.3,0.3$ \\
\hline \multicolumn{5}{|l|}{ Histology } \\
\hline \multicolumn{5}{|l|}{ Liver } \\
\hline No abnormality & 2 & 1 & 1 & 2 \\
\hline Focal necrosis & 2 & 3 & 1 & 0 \\
\hline Lymphocytic infiltration & 0 & 2 & 0 & 0 \\
\hline \multicolumn{5}{|l|}{ Kidney } \\
\hline No abnormality & 4 & 5 & 2 & 2 \\
\hline Severe glomerulonephritis & 0 & 1 & 0 & 0 \\
\hline
\end{tabular}

NTBC, 2(-2-Nitro-4-trifluoromethylbenzoyl)-1,3 cyclohexanedione; AST, aspartate aminotransferase

${ }^{a}$ Values are expressed as means \pm SEM

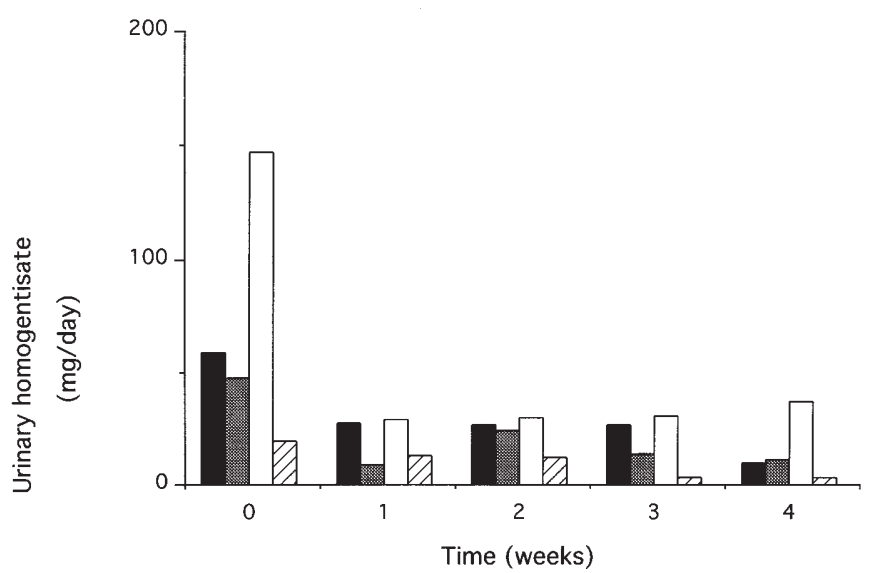

Fig. 6 Effect of 4-week administration of NTBC $(25 \mu \mathrm{g} /$ day, except weekends) on urinary HGA excretion, as homogentisate, in four alkaptonuric mice. Black bars, alkaptonuric mouse \#1; gray bars, \#2; white bars, \#3; hatched bars, \#4

tic (i.e., mice can endogenously synthesize ascorbic acid; Levine 1986). Ascorbic acid impedes the conversion of HGA to benzoquinoneacetate, an intermediary metabolite in oxidation (Fig. 1), and inhibits the generation of oxygen radicals in the development of ochronotic arthritis (Martin and Batkof 1987). The effect of ascorbic acid on the amount of HGA excreted by patients with alkaptonuria was inconclusive (Sealock et al. 1940; Neuberger et al. 1947, Wolff et al. 1989; Simoni et al. 1994; Pradeep et al. 1996). We presume that NTBC administered to alkaptonuric patients has a beneficial effect on ochronosis as well, by blocking the biosynthesis of HGA, the source of ochronotic pigments.

Attempts to treat alkaptonuria with NTBC could be aimed at either treating the disease or preventing its complications. Accordingly, NTBC could be used to relieve the intolerable arthralgia in patients with alkaptonuria, based on the assumption that it may suppress the oxygen radicalinduced inflammation in connective tissues. NTBC adminis- tered over the long term during asymptomatic periods may also delay or prevent complications, by suppressing the progression of pathologic changes in connective tissue.

Grompe et al. (1995) observed no side effects, no teratogenicity, and no tumorigenicity in mice with hereditary tyrosinemia type I treated with NTBC. Our histological findings support a part of their observations. Furthermore, no side effects were encountered in patients with hereditary tyrosinemia type I who were successfully treated with an oral daily dose of NTBC of $0.1-0.6 \mathrm{mg} / \mathrm{kg}(10 \%-60 \%$ of the dose used for mice in the present study) (Lindstedt et al. 1992). NTBC-induced hypertyrosinemia may have no adverse effects, as HPPD deficiency can be compatible with normal development in some humans (Mitchell et al. 1995), and, further, HPPD-deficient mice were also apparently healthy (Endo et al. 1991).

For either curative or preventive purposes, the use of NTBC together with ascorbic acid would be preferable, since, as pointed out by Sealock et al. (1940), it is possible that adequate tissue concentrations of ascorbic acid may prevent the deposition of ochronotic pigment.

These findings suggest that NTBC may be a promising agent for the treatment of alkaptonuria. Clinical trials of NTBC would be warranted in the future.

Acknowledgments The authors are grateful to Dr. X. Montagutelli, of the Pasteur Institute for providing the alkaptonuric mice. We thank Sumitomo Pharmaceuticals for providing the NTBC. We also thank Mr. Y. Sakamoto, Medical School of Osaka University, for analyzing the amino acids in plasma. In addition, we would like to express our appreciation to Mr. Brian Quinn for his critical reading of the manuscript.

\section{References}

Ellis MK, Whitfield AC, Gowans LA, Auton TR, Provan WM, Lock EA, Smith LL (1995) Inhibition of 4-hydroxyphenylpyruvate dioxygenase by 2-(2-nitro-4-trifluoromethylbenzoyl)-cyclohexane1,3-dione and 2-(2-chloro-4-metanesulfonylbenzoyl)-cyclohexane1,3-dione. Toxicol Appl Pharmacol 133: 12-19 
Ellis MK, Whitfield AC, Gowans LA, Auton TR, Provan WM, Lock EA, Lee DL, Smith LL (1996) Characterization of the interaction of 2-[2-nitro-4-(trifluoromethyl)benzoyl]-4,4,6,6-tetramethylcyclohexane-1,3,5-trione with rat hepatic 4-hydroxyphenylpyruvate dioxygenase. Chem Res Toxicol 9: 24-27

Endo F, Katoh H, Yamamoto S, Matsuda I (1991) A murine model for type III tyrosinemia: Lack of immunologically detectable 4hydroxyphenyl-pyruvic acid dioxygenase enzyme protein in a novel mouse strain with hypertyrosinemia. Am J Hum Genet 48: 704-709

Fernández-Cañón JM, Granadino B, Beltrán-Valero de Bernabé D, Renedo M, Fernández-Ruiz E, Peñalva MA, Rodríguez de Córdoba S (1996) The molecular basis of alkaptonuria. Nature Genet 14: 19-24

Garrod AE (1908) The Croonian Lectures on inborn errors of metabolism. Lecture II. Alkaptonuria. Lancet II: 73-79

Grompe M, Lindstedt S, Al-Dhalimy M, Kennaway NG, Papaconstantinou J, Torres-Ramos CA, Ou C-N, Finegold M (1995) Pharmacological correction of neonatal lethal hepatic dysfunction in a murine model of hereditary tyrosinemia type I. Nature Genet 10: 453-460

Kamoun P, Coudé M, Forest M, Montagutelli X, Guénet JL (1992) Ascorbic acid and alcaptonuria. Eur J Pediatr 151: 149

Kihara T, Yasuda M, Watanabe H, Suenaga Y, Shiokawa S, Wada T, Nonaka S, Suzuki T, Nobunaga M (1994) Coexistence of ochronosis and rheumatoid arthritis. Clin Rheumatol 13: 135-138

La Du BN, Zannoni VG, Laster L, Seegmiller JE (1958) The nature of the defect in tyrosine metabolism in alcaptonuria. J Biol Chem 230: 251-260

La Du BN (1995) Alkaptonuria. In: Scriver CR, Beaudet AL, Sly W, Valle D (eds) The metabolic and molecular basis of inherited disease. 7th edn. McGraw-Hill, New York, pp 1371-1386
Levine M (1986) New concepts in the biology and biochemistry of ascorbic acid. N Eng J Med 314: 892-902

Lindstedt S, Holme E, Lock EA, Hjalmarson O, Strandvik B (1992) Treatment of hereditary tyrosinaemia type I by inhibition of 4hydroxyphenylpyruvate dioxygenase. Lancet 340: 813-817

Martin JP, Batkof B (1987) Homogentisic acid autooxidation and oxygen radical generation: Implications for the etiology of alkaptonuric arthritis. Free Radical Biol Med 3: 241-250

Mitchell GA, Lambert M, Tanguay RM (1995) Hypertyrosinemia. In: Scriver CR, Beaudet AL, Sly W, Valle D (eds) The metabolic and molecular basis of inherited disease. 7th edn. McGraw-Hill, New York, pp 1077-1106

Montagutelli X, Lalouette A, Coudé M, Kamoun P, Forest M, Guénet J-L (1994) Aku, a mutation of the mouse homologous to human alkaptonuria, maps to chromosome 16. Genomics 19: 9-11

Neuberger A, Rimington C, Wilson JMG (1947) Studies on alcaptonuria. 2. Investigations on a case of human alkaptonuria. Biochem J 41: 438-449

Pradeep JK, Kehinde EO, Doar AS (1996) Symptomatic response to ascorbic acid. Brit J Urol 77: 319-320

Sealock RR, Galdston M, Steele JM (1940) Administration of ascorbic acid to an alkaptonuric patient. Proc Soc Exp Biol Med 44: 580-583

Simoni RE, Gomes LNF, Faria MS, Neto JB, Costa de Oliveira ML (1994) Monitoring of a one-month ascorbic acid therapy in an alcaptonuric child; determination by HPLC. J Inher Metab Dis 17: 632-633

Wolff JA, Barshop B, Nyhan WL, Leslie J, Seegmiller JE, Gruber H, Garst M, Wnter S, Michals K, Matalon R (1989) Effects of ascorbic acid in alkaptonuria: Alteration in benzoquinone acetic acid and an ontogenic effect in infancy. Pediatr Res 26: 140-144 